\title{
The Resonance of Music Across Cultures
}

\author{
Rolf J. Goebel, Ph.D. \\ Distinguished Prof. of German, Emeritus, University of Alabama in Huntsville. \\ Email: Goebelr@uah.edu
}

\begin{abstract}
What predestines music to be able to transgress geo-cultural boundaries? I argue that music's sensuous, bodily-affective immediacy requires a mode of cross-cultural translation via what I call auditory resonance-the spontaneous attunement of listeners with the sonic presence of music through media-technological transmission despite vestiges of cultural colonialism and other sociopolitical barriers. I trace such resonance effects from German Romanticism through our global present, focusing especially on the conversations between two Japanese cultural figures, the conductor Seiji Ozawa and the novelist Haruki Murakami. These texts show that the category of auditory resonance is more suitable for addressing European music's global significance than its traditional claims to transcultural universality.
\end{abstract}

\section{Keywords}

Music, resonance, immediacy, presence, media technologies, cultural translation, Wilhelm Heinrich Wackenroder, Walter Benjamin, Seiji Ozawa, Haruki Murakami

What is music's special role in intercultural exchanges? What is it that predestines music, especially European classical music, to be able to transgress geo-cultural boundaries? Is it perhaps music's universality, which, according to the Romantic metaphysics of music, transcends the conflicts of the misery of life into an absolute realm of pure aesthetic beauty and spiritual truth? Or, if this sounds too speculative, is it perhaps the musical material's sensuous immediacy, which seems to appeal directly to listeners from diverse cultures? This is the position held by Kathleen Marie Higgins. Although she concedes that cross-cultural encounters in music can be mired in ethnocentricity and sectarian divisions, Higgins assumes that unlike literary texts, which often depend on verbal translation to be understood, music, whether performed live or via technological media, possesses a special kind of immediacy that "neither requires nor allows for translation, and it communicates with urgency because it is so direct" (Higgins 2012, 181). ${ }^{i}$ Certainly Higgins is right that the understanding of music-whether instrumental compositions or the accompaniment of song texts or opera libretti-does not rely on the type of verbal translation that textual 
artifacts require when read outside their original language. But does music need no crosscultural translation at all?

I propose that music's intuitively felt immediacy requires a mode of cross-cultural translation via what I call auditory resonance-the spontaneous experience of a sensuous, bodily-affective attunement of listeners with the sonic presence of music. I am extending here some positions proposed by the German sociologist Hartmut Rosa. He defines resonance in a wide range of social contexts as a responsive relationship to the world, which presupposes "that both subject and world be sufficiently 'closed' or self-consistent so as to each speak in their own voice, while also remaining open enough to be affected or reached by each other" (Rosa 2019, 174). For Rosa, music conveys "an irreducible aesthetic excess" beyond its purely signifying function, which opens up realms of experience inaccessible to other sign systems (94). In fact, Rosa goes so far as arguing that in music, "our relationship to the world as a whole becomes tangible and thus can be both modulated and modified" (Rosa 2019, 94). Moreover, the "experience of music suspends the division between self and world, transforming it in a way into a pure relationship": in the "universe of sound," affects like strife, loneliness, yearning, love, etc., find particularly nuanced articulation as relational factors between human subjects and the world (Rosa 2019, 94). Rosa's insights are especially applicable to cross-cultural relationships, which nowadays are often forged through media-technological interconnectivity. Here I disagree with Rosa, who contrasts the authenticity of music's ability to enlarge and intensify human relationships of genuine resonance with the presumably standardizing, flattening, and reductive tendency of the computer screen, which, he says, leads "to a potential uniformity or mono-modularization of our relationship to the world" (Rosa 2019, 91). Although this is indeed often the case in our obsessive production and consumption of social media postings, popular music streaming, and so forth, I think that digital interconnectivity, especially in the realm of music, can also yield profoundly nuanced and intensifying results crucial for a genuinely crosscultural understanding between peoples of various personal backgrounds, ethnic origins, and political ideologies.ii

Questioning traditional arguments about an ontological difference between live performances and their media-technological reproduction, Philip Auslander has proposed that "historically, the live is actually an effect of mediatization, not the other way around" because before the advent of various recording technologies, the concept of a presumably more authentic "live" experience did not exist (Auslander 1999, 51). Similar to Auslander's notion of live performance as a retroactive media-effect, I propose that in our global media age, auditory resonance produces music's immediacy across geopolitical borders as a technologically facilitated effect, an illusion that is felt absolutely real. Once heard as a technologically produced sense of sonic presence, this effect draws attention to the fact that music's sensuous appeal is not directly understandable across cultural 
divides but contains a potentiality of multiple, inexhaustible meanings that require active modes of interpretation, critique, and re-appropriation in one's own cultural context. Although auditory rather than textual, this cross-cultural translation's framework is by necessity verbally discursive because, as Lawrence Kramer has argued (Kramer 2011), verbal language is the necessary medium in which any kind of musical understanding can be articulated and preserved. If this translational resonance is successful-and there is never any guarantee that it is-music may exert its aesthetic, intellectual, and emotional power despite and against material obstacles-economic disparities, ethnocentrisms, racial, gender, and class differences - that mark today's global capitalist consumer society as well as areas of the world resisting, or left out of, its ideology.iii

Even a German Romantic writer like Wilhelm Heinrich Wackenroder was keenly aware of this situation. He provides a thoroughly metaphysical interpretation of the underlying linkage between sonic resonance and what we nowadays call cultural imperialism. For Wackenroder, music's direct identity of signifier and signified, beyond the stiflingly abstract rationality of concepts, resonates sensuously with the affective strings in the depth of the human heart, evoking a seemingly immediate, intuitive understanding and a myriad of free, visual and verbal associations in the human imagination. In his essay "Some Words About Generality, Tolerance, and Love for Humankind in the Arts, "iv Wackenroder argues that despite strife and misunderstandings among peoples from various countries, in the eyes of God, all artistic manifestations are equally legitimate and pleasing as authentic expressions of the divine spark in diverse cultures and historical periods. Thus, to God, a Gothic temple is as pleasing as a Greek temple and the "raw war music of the wild peoples" is "as lovely a sound" as the artful choruses and church hymns of the Western world (Wackenroder 1991, 87). In spite of this phrasing, which clearly reflects the colonialist ideology and exoticism of his time, Wackenroder explicitly advocates for what we would nowadays call an anti-ethnocentric worldview. He criticizes those who consider their own location on the world map as the "center of gravity of the whole," while their spirit lacks the wings of the imagination "for flying around the entire globe" in order to perceive it in its culturally rich and diverse entirety. Such Eurocentric views, he insists, presumptuously judge everything beautiful by their own standards without considering that the cultures thus denigrated might in turn also engage in similarly arrogant judgments about European values (Wackenroder 1991, 87).

What I find interesting is that Wackenroder's metaphysical idealism, for all its speculative ideas and rhetorical excess, contains a self-subversive dynamic anchored in the material realities of the global politics of his day, including the rise of Western cultural hegemony. A particular brand of musical imperialism was particularly prevalent in the European capitals of the 19th century. In his Arcades Project (1927-40), Walter Benjamin notes that together with the "mechanical music" offered by fashionable media of sonic reproduction like the "theatrophone," composers like Félicien-César David (1810-76) wrote a type of 
panoramic music with enticing titles like Le Désert, Christoph Colomb, and Herculanum. This operatic music evokes cross-cultural resonances between the metropolitan centers of the industrial capitalist consumer society and faraway locales. As a musical reflection of Orientalist phantasies, this music primarily satisfied the Parisian bourgeoisie's desire for imaginary travels while also supporting events like the welcome extended to an Arab political delegation visiting the French capital in the 1860s (Benjamin 1999, H1, 5, 204). While they seem to be of purely aesthetic prevalence, signaling an attitude to benign cultural openness, these fantasies of cross-cultural exchange actually sublimate and perpetuate deep-seated Eurocentric values and colonialist enterprises that have frequently marked the metropolitan sense of global music.

In our time, Benjamin's critique of musical colonialism resonates with current paradigms like postcolonialism and the deconstructive critiques of Western hegemony. Their theories have given rise to musicology's project of decentering the dominant canonicity of Western music, which is sometimes seen as silencing or marginalizing the authentic voices of other, indigenous musical traditions. Therefore, musicologists like George E. Lewis envisions a "continuously interrogatory, networked project of decolonization" as part of the subversive cultural logic of the "Eurological," which, he proposes, differs from the selfenclosed, hegemonic position of the Eurocentric by its politically progressive model of hybridity and creolization: "A creolized contemporary music culture would be race-aware, not race-deaf, establishing a mosaic identity that recognizes historical, geographical and cultural cross-connections-not so much to achieve diversity as to pursue a new complexity that promises far greater creative depth" (Lewis, n.d., n.p.]

My admittedly sketchy reconstruction of some voices from the Western critique of musical imperialism since Romanticism opens up a conceptual horizon in which we can appreciate, contrapuntally as it were, the counter-perspective of two contemporary voices: the eminent classical conductor Seiji Ozawa and the popular novelist Haruki Murakami." Both belong to the cultural elite of present-day Japanese thoroughly steeped in European and American traditions, exemplifying the complex hybridity of cultural exposures, the montage-like simultaneity of classical Japanese heritage with rampant Westernization typical of the country since the Meiji period in the 19th century. Between November 2010 and July 2011, Murakami conducted a series of interviews with Ozawa on a wide range of musical issues, from the compositions of Beethoven, Brahms, and others to obsessive record collecting, the relation of writing to music, and the performance styles of various orchestras and conductors. Interestingly, Murakami stresses that their exchange was based on the principle of discursive resonance: "[W] hat I often heard [from Ozawa] at the same time was the resonance of my own heart." Ozawa's utterances were either recognizable as actually having long been a part of Murakami himself or, conversely, coming to him as a complete surprise (xv). At one point, they explore what makes the music of the late Romantic Austrian composer Gustav Mahler "particularly universal or 
cosmopolitan" (Murakami 2016, 185). Murakami starts by stressing the unique montagecharacter of Mahler's work, which juxtaposes many radically diverse and heterogeneous elements, seemingly without logical connections, such as traditional German, Jewish, and Bohemian music, fin-de-siècle overripeness, philosophical propositions, Christian dogma, Asian worldviews. This combinatory aesthetics, Murakami muses, may offer "plenty of openings" where a non-Western conductor like Ozawa "can make his own special inroads" (Murakami 2016, 185).

Ozawa agrees, citing as an example for this "sort of universal opening" the difference between the "special kind of sorrow" held by the Japanese and "Jewish sorrow or European sorrow." Hence Ozawa argues, "a performance of Western music that also makes full use of Japanese sensibilities," assuming the technical excellence of the performance, "has its own raison d'être" (Murakami 2016, 186). Despite the conductor's use of the term "universal," for Murakami and Ozawa, an understanding between the finde-siècle Jewish composer and the modern Japanese conductor is not predicated on a metaphysical notion of the time- and culture-transcending totality or even predominance of Western music, but rather on an immanent resonance based on technical characteristics of the sensuously sonic and spiritual material of particular compositions. Precisely because Mahler's montage-technique does no longer rely on the relatively unified and closed structure of the classical work of art, it contains ruptures between disparate elements through which Eastern sensibilities can enter from their distinctly own origins of culture, sensibilities, and hermeneutic presuppositions. These cross-cultural resonances are not limited to classical music. For Ozawa, for instance, Louis Armstrong's special and "indescribable" performance style resembles the traditional notion of artistic shibumi in Japan, the mature artist's attainment of "austere simplicity and mastery" (Murakami 2016, 210). Murakami's and Ozawa's discursive musings, even if they are rather personal and impressionistic, are part of a cultural translation process that responds to such resonant correspondences with a sensibility for music's seemingly immediate presence sharpened by the instruments of analytic reflection shared in an interdisciplinary context by a musician and a novelist.

As Murakami stresses, Mahler's music was in a cultural sense inherently transgressive. The composer, as the writer puts it, "half consciously, but also half unconsciously, departed from what you might call orthodox German music" (Murakami 2016, 187). This might have been a reason why a conductor like Herbert von Karajan, steeped as he was in the tradition from classical-Romantic repertoire to the Second Viennese School, seemed to project his own modernist understanding of Arnold Schönberg and his followers onto Mahler's lateRomantic music, "dragging him into the area where he [Karajan] himself is at his best" (Murakami 2016, 188). Moreover, after Mahler's music had been silenced during the Nazi regime, Murakami continues, "it fell to America, and not Europe, to become the powerhouse for the current Mahler revival" (Murakami 2016, 189), which was significant 
shaped the path-breaking conducting of Leonard Bernstein. In this way, Mahler's music was given new life "outside of the European home base" (Murakami 2016, 189; emphasis in the original). What Murakami hints at here is the notion that cross-cultural musical resonance depends on an intentional or subconscious desire for extraterritorial projection on the part of a European composer, for departing or at least suspending one's cultural origins, which in turn paves the ground for a correspondingly congenial receptivity by performers and listeners from another culture.

In his short story "Carnaval," recently translated into English, Murakami addresses further issues of musical resonance from the perspective of two fictional Japanese listening to Robert Schumann's piano cycle Carnaval. At a concert, the nameless narrator meets F*, who he feels is an unusually ugly but intellectually refined and attractive, if wholly mysterious, even secretive woman. They develop a platonic, aesthetic friendship around their shared love for classical music, discovering that Schumann's Carnaval is their absolutely favorite composition. Similar to Mahler's symphonies in Murakami's conversation with Ozawa, Schumann's piano music figures as "incoherent," as a beautiful kaleidoscope that at first appears "somehow beyond the bounds of human intellect" (177). But then they discover that it was precisely the rambling eccentricity of Schumann's compositorial style, its rejection of classical forms like the sonata, and its lack of a "solid foundation and content" that contributed to the rise of Romantic music (Murakami 2021, 180). Almost obsessively, the friends listen to every recording of the cycle they can lay their hands on. They agree that the most important thing is to indulge in "the feeling of almost aimlessly sharing something we were passionate about" (Murakami 2021, 181). Thus, the resonance between Schumann's work and its Japanese listeners is primarily based not on an intellectual analysis, as was the case with Murakami's and Osawa's conversations on Mahler, but on a deeply intuitive, sensuously enthusiastic response to the music's seemingly groundless depth of meaning.

But there are other, more disturbing reasons for this type of resonance. As $\mathrm{F}^{\star}$ explains, Schumann suffered from "terrible auditory hallucinations," uncontrollable trembling, and suicidal urges, and although Carnaval, being an earlier work, does not yet fully reflect these afflictions, its depiction of the carnival festival explores an unsettling contrast between wearing a playful mask and the disturbing "specters lurking inside the psyche" under the deceptive surface appearance (Murakami 2021, 183-84). As $F^{*}$ remarks, all people wear such masks, and it is the narrator's fear to discover what lies beneath his friend's own surface, not her unattractive looks, that prevents him from trying to make love to her (Murakami 2021, 187). $F^{*}$ exudes a special kind of aura that emerges from the tension between her surface appearance and "a kind of power that encroached on others' minds and hearts" (191). Eventually, $\mathrm{F}^{\star^{\prime}} \mathrm{s}$ secret is pitilessly revealed by the newspapers: She and her husband have been arrested for a major financial investment fraud; she then totally disappears, leaving the narrator haunted by the powerful memories of the episode. 
The fragility of the cross-cultural resonance between a German Romantic composer and his contemporary Japanese listeners is all the more striking given that Murakami here makes absolutely no reference to any particularly cultural frameworks for Schumann's reception in Japan. In contrast to the writer's conversations with Ozawa about Mahler and Armstrong, which at least tangentially evoke concepts of Japanese sensibility-"sorrow", shibumi-, the immersion of $\mathrm{F}^{*}$ and her friend in the music of Schumann occurs largely in a cultural vacuum, suggested only vaguely to be a metropolitan, late capitalist, postmodern space where Western music is freely accessible to individual listeners through live concerts and countless recordings. The narrator and his friend seem to live in a private non-location that allows them to cultivate an illusion of European classical music's sensuous immediacy whose imaginary affordances of aesthetic beauty are only toward the end disrupted by the stark realities of financial corruption and legal crime. The tragedy of Murakami's Schumann aficionados is that they react to music's illusory autonomy in diametrically opposed but equally calamitous ways: while the narrator simply seeks to cultivate a kind of musical aestheticism with a woman he is otherwise incapable of loving, $\mathrm{F}^{*}$ of course is aware of the corruptibility of her own musical refinement by her financial greed that she is unwilling to admit to her friend. In this sense, $\mathrm{F}^{*^{\prime}} \mathrm{s}$ problem is indicative of the conflict between music appreciation-which is often regarded as an ideal immersion in the beauty of a composition for its own sake-and the listening subject's morality.

Ultimately then, the initially captivating, deeply satisfying resonance between Schumann's Carnavaland the two Japanese music lovers is endangered by the devastating dissonance between musical meaning and personal listening circumstances. Like Schumann's composition, whose abysmal meaningfulness can never be fully exhausted by hermeneutic analysis or countless recordings, $\mathrm{F}^{*} \mathrm{~s}$ character-her supreme sensitivity to music hiding her moral depravity-ultimately eludes the narrator's compass of understanding, trapped as he is in his masculist musings about $\mathrm{F}^{*}$ appealingly artistic imagination transfigured by her presumably ugly appearance. In this sense, the situation, which might require a more self-reflexive analysis than both protagonists are willing to engage in, reveals not only the possibilities, but also and especially the limitations of the musical resonance's cultural translatability under adverse personal and social circumstances.

I hope to have shown that the category of cross-cultural translatability based on auditory resonance is more convincing than European music's claim to transcultural universality. Whereas the ideal of music's universality relies on a Romanticized notion of metaphysical transcendence, resonance combines the bodily-affective presence of tangible musical material with the need for interpretative actualization. In other words, in the age of mediatechnological interconnectivity, resonance creates musical meaningfulness as something that transverses and trans gresses, rather than transcends, geopolitical boundaries and the 
experiential horizons of individual listeners. Music is never free from ideology, political power, and corruption, but neither is it necessarily complicit with these circumstances or can be totally co-opted by them. In this ambivalent context, musical resonance must be actively desired, explored, and cultivated through attentive listening. Murakami popularizes the promises, successes, and failures of such cross-cultural translatability, showing that literary fiction supplies particularly insightful strategies for elucidating the mysteries of musical resonance in ways that appeal to a broad audience beyond the expert knowledge of musicologists. In this sense, fictional representations always point to something beyond music's own sonic presence, demonstrating the power of the literary imagination to explain what music itself cannot fully say. ${ }^{\text {vi }}$

\section{Acknowledgement}

This article is the slightly revised version of my keynote lecture at the 2nd Rupkatha International Open Conference on Recent Advances in Interdisciplinary Humanities, 2021 (Virtual), August 28-30, 2021. I thank the organizers for the kind invitation and Dr. Albrecht Classen, University of Arizona, for nominating me and for his helpful comments on an earlier draft of the lecture.

\section{Declaration of Conflicting Interests}

The author(s) declared no potential conflicts of interest with respect to the research, authorship, and/or publication of this article.

\section{Notes}

\footnotetext{
' Among the types of crosscultural encounters in music, Higgins lists performances by members form multiple cultures and of musical works from various cultures, fusions of multiple musical styles, inclusive modes of participatory music-making, and listening to recordings of music from cultures other than one's own (179).

ii For a survey of the historical development of the dialectical interaction between rationality and bodilyaffective resonance in philosophical, neuro-physiological, and media-technological discourses, mainly from the Enlightenment to the present, see ErImann 2014.

iii In some ways, sonic resonance shares features with the phenomenon of atmospheres as spatial extensions of bodily-affective and immersive experiences in various aesthetic contexts, including music. See, for instance, Böhme 2017.

iv All translations from Wackenroder are my own.

${ }^{\vee}$ For an illuminating introduction to Murakami's life, fiction and aesthetic views, see Rubin 2005.

vi For a discussion of the interaction of sound/music with media-technological reproducibility and literary representations, see Goebel 2017.
} 


\section{References}

Auslander, Philip (1999). Liveness: Performance in a Mediatized Culture. London, New York: Routledge.

Benjamin, Walter (1999). The Arcades Project. Trans. Howard Eiland and Kevin McLaughlin. Cambridge, Mass. and London: Belknap Press of Harward University Press.

Böhme, Gernot (2017). The Aesthetics of Atmospheres. Ed. Jean-Paul Thibaud. London, New York: Routledge.

Erlmann, Veit (2014). Reason and Resonance: A History of Modern Aurality. New York: Zone Books.

Goebel, Rolf J. (2017). Klang im Zeitalter technischer Medien: Eine Einführung. Wien: Passagen Verlag.

Higgins, Kathleen Marie (2012). The Music Between Us: Is Music a Universal Language? Chicago, London: Chicago University Press.

Kramer, Lawrence (2011). Interpreting Music, Berkeley, Los Angeles, London: University of California Press.

Lewis, George E. [n.d.] "New Music: Decolonization in Eight Difficult Steps." Outernational \# 14. https://www.van-outernational.com/lewis-en.

Murakami, Haruki (2016). Absolutely On Music: Conversations with Seiji Ozawa. Trans. Jay Rubin. New York: Vintage-Penguin Random House.

-- (2021). "Carnaval." In First Person Singular: Stories. Trans. Philip Gabriel. New York: Knopf, 163-97.

Rosa, Hartmut (2019). Resonance: A Sociology of Our Relationship to the World. Trans. James C. Wagner. Cambridge, UK, Medford, MA: Polity Press.

Rubin, Jay (2005). Haruki Murakami and the Music of Words. London: Vintage-Random House.

Wackenroder, Wilhelm Heinrich (1991). "Einige Worte über Allgemeinheit, Toleranz und Menschenliebe in der Kunst." In Sämtliche Werke und Briefe. Historisch-Kritische Ausgabe. Ed. Silvio Vietta and Richard Littlejohns. Vol. 1: Werke. Ed. Silvio Vietta. Heidelberg: Carl Winter.

\section{Author's Biographical Note:}

Rolf J. Goebel, Ph.D. holds degrees from Brown University (M.A. in English, 1977), the University of Kiel (Staatsexamen in German and English, 1979), and the University of Maryland (Ph.D. in German Language and Literature, 1982). From 1982-2020 he taught German language and culture at the University of Alabama in Huntsville. He is now Distinguished Professor Emeritus at this institution. In addition to numerous articles, book reviews, and conference papers, he has published four monographs: Kritik und Revision: Kafkas Rezeption mythologischer, biblischer und historischer Traditionen (1986); Constructing China: Kafka's Orientalist Discourse (1997); Benjamin heute: Großstadtdiskurs, Postkolonialität und Flanerie zwischen den Kulturen (2001); and Klang im Zeitalter technischer Medien: Eine Einführung (2017). He is also a co-author of A Franz Kafka Encyclopedia (with Richard T. Gray, Ruth V. Gross und Clayton Koelb, 2005), and has edited $A$ Companion to the Works of Walter Benjamin (2009). 